\title{
Aderência bacteriana in vitro a lentes intra-oculares de polimetilmetacrilato e de silicone
}

\author{
In vitro bacterial adherence to silicone and polymetylmethacrylate intraocularlenses
}

\author{
Claudete Inês Locatelli ${ }^{1}$ \\ Gelsa Edith Englert ${ }^{2}$ \\ Sérgio Kwitko ${ }^{3}$ \\ Amauri B. Simonetti ${ }^{4}$
}

\section{RESUMO}

Objetivos: Verificar a aderência bacteriana a lentes intra-oculares de silicone e de polimetilmetacrilato como possível fator de risco no desenvolvimento de endoftalmite pós-operatória, utilizando-se um modelo in vitro com três microrganismos potencialmente patogênicos. Métodos: As análises foram realizadas com cepas de Staphylococcus aureus ATCC 29213, Staphylococcus epidermidis (amostra clínica) e Pseudomonas aeruginosa ATCC 27853 incluindo a determinação de curvas de crescimento, testes para verificação de produção de cápsula, avaliação da hidrofobicidade, testes de aderência a diferentes materiais, microscopia óptica, microscopia eletrônica de varredura e microscopia de força atômica. Resultados: A produção de cápsula e a aderência das três diferentes cepas não mostraram qualquer relação com a quantidade de microrganismos; em relação às lentes intra-oculares de polimetilmetacrilato e de silicone, não houve diferença estatisticamente significativa na aderência de $S$. aureus e $S$. epidermidis; $P$. aeruginosa foi o microrganismo mais aderente a ambos os materiais. A microscopia eletrônica de varredura confirmou estes achados em relação à aderência, ao peso que a microscopia de força atômica evidenciou a produção de biofilme pelas cepas de $S$. aureus, $S$. epidermidis e $P$. aeruginosa. Conclusões: Constatou-se, in vitro, que os materiais analisados não diferiram com relação à taxa de aderência bacteriana, porém, $P$. aeruginosa apresentou maior eficiência de adesão entre as bactérias testadas. Todas as cepas produziram biofilme. Silicone foi o material mais hidrofóbico, quando comparado ao polimetilmetacrilato.

Descritores: Aderência bacteriana; Lentes intra-oculares; Polimetilmetacrilato; Silicones; Pseudomonas; Infecções estafilocócicas

\footnotetext{
Microbiologista do Serviço de Oftalmologia do Hospital de Clínicas de Porto Alegre.

2 Doutora em Engenharia do Departamento de Metalurgia

da Universidade Federal do Rio Grande do Sul.

${ }^{3}$ Doutor em Oftalmologia pelo Serviço de Oftalmologia do Hospital de Clínicas de Porto Alegre.

${ }^{4}$ Professor Adjunto do Departamento de Microbiologia do Instituto de Ciências Básicas da Saúde da Universidade Federal do Rio Grande do Sul.

Fonte de Auxílio: Conselho Nacional de Desenvolvimento Científico e Tecnológico (CNPq)

Endereço para correspondência: Claudete Inês Locatelli, Rua Barão do Amazonas, 1040/206

Porto Alegre (RS) CEP 90670-001

E-mail: clocatelli@hcpa.ufrgs.br

Recebido para publicação em 05.05.2003

Versão revisada recebida em 10.10.2003

Aprovação em 14.11.2003

Nota Editorial: Pela análise deste trabalho e por sua anuência na divulgação desta nota, agradecemos aos Drs.

Humberto de Castro Lima e Paulo Ricardo de Oliveira
}

\section{INTRODUCÃ̃O}

Cirurgia de catarata para implante de lentes intra-oculares (LIO) pode levar à endoftalmite pós-operatória e, ainda que raramente, à perda total da visão no olho acometido em até $50 \%$ dos $\operatorname{casos}^{(1-3)}$. A microbiota endógena conjuntival é a primeira suspeita quando se está pesquisando a causa de infecções oculares pós-traumáticas e pós-operatórias ${ }^{(4-9)}$. Diferentes tipos de bactérias podem causar endoftalmite sendo estafilococos coagulase-negativos, mais especificamente $S$. epidermidis, os agentes mais comumente isolados $^{(6,10-13)}$. Sabe-se que $S$. epidermidis tem habilidade de se aderir e proliferar em superfícies de polímeros, especialmente lentes intra-oculares, secretando uma matriz extracelular viscosa (biofilme) que o protege contra antibióticos, bem como dos mecanismos de defesa do hospedeiro ${ }^{(10,14-16)}$. A adesão bacteriana a lentes intra-oculares e a produção de biofilme parecem 
estar associadas à sua carga eletrostática superficial e às cepas produtoras de cápsula ${ }^{(12,17)}$, variando de intensidade conforme o tipo de lente testado ${ }^{(11,18)}$.

O objetivo deste estudo foi verificar a aderência bacteriana a lentes intra-oculares de silicone e de polimetilmetacrilato (PMMA), como possível fator de risco no desenvolvimento de endoftalmite pós-operatória, através de um modelo in vitro, utilizando-se três microrganismos potencialmente patogênicos.

\section{MÉTODOS}

\section{Microrganismos}

Foram utilizadas cepas de Pseudomonas aeruginosa ATCC 27853, Staphylococcus aureus ATCC 29213 e isolado de amostra clínica de Staphylococcus epidermidis (identificado de acordo com as normas técnicas da NCCLS). O estoque das culturas foi mantido em caldo de infusão de cérebro e coração (BHI) contendo $20 \%$ de glicerol e congelado a $-20^{\circ} \mathrm{C}$. Para a verificação da presença de cápsula foi também utilizado um isolado clínico de Klebsiella pneumoniae como controle positivo.

\section{Lentes intra-oculares}

Foram utilizadas lentes intra-oculares de PMMA provenientes da CILCO ${ }^{\circledR}$ Alcon Surgical, Inc.(Fort Worth, Texas USA) modelo MC50BD peça única com 6,5 mm de diâmetro na área óptica e lentes intra-oculares de silicone do laboratório Allergan Medical Optics ${ }^{\mathrm{TM}}$ (Irvine, Califórnia -USA) modelo SSM26NB três peças, das quais foram retiradas as alças, com 6,0 mm de diâmetro na área óptica.

\section{Avaliação da presença de cápsula}

Para verificar a produção de cápsula foram utilizados os métodos de coloração com Vermelho Congo ${ }^{(19)}$, em três repetições, método qualitativo da safranina ${ }^{(20)}$, em três repetições e o micrométodo quantitativo da safranina ${ }^{(21)}$, em 15 repetições. Klebsiella pneumoniae foi utilizada como controle positivo. Os resultados foram expressos em cruzes para os dois primeiros métodos e em densidade óptica $\left(\mathrm{DO}_{490}\right)$ para o micrométodo quantitativo.

\section{Avaliação da hidrofobicidade bacteriana}

Para o teste do sulfato de amônio ${ }^{(11)}, 15 \mu$ l de cada suspensão bacteriana foram misturados com diferentes concentrações de sulfato de amônio ( $1 \mathrm{M}, 1,5 \mathrm{M}, 2 \mathrm{M}, 2,5 \mathrm{M}$ e 3M) em uma lâmina de vidro, levemente agitados e, a seguir, foi observada a formação de grumos. Este ensaio foi realizado em triplicata para cada bactéria testada.

O teste do xileno mede fotometricamente a distribuição bacteriana em um sistema de duas fases ${ }^{(21)}$. Foram adicionados $250 \mu \mathrm{l}$ de $p$-xileno às suspensões bacterianas, sendo os frascos agitados por 1 minuto e a densidade óptica medida em
$600 \mathrm{~nm}\left(\mathrm{DO}_{600}=0,8\right)$. O conteúdo bacteriano da fase aquosa foi determinado após um período de repouso de 10 minutos. Este ensaio foi realizado em sextuplicata para cada bactéria testada. Neste método, considera-se que uma maior interação dos microrganismos com um líquido apolar ( $p$-xileno) indica maior hidrofobicidade.

A técnica da gota séssil(22) foi utilizada para verificar a característica superficial dos microrganismos e das lentes através da medida do ângulo do raio entre os dois. Esta técnica foi realizada com algumas modificações. Foram adicionados $10 \mu \mathrm{l}$ de cada amostra contendo $10^{6} \mathrm{~mL}^{-1}$ e o ângulo do raio medido em graus, pelo aumento ou diminuição do volume da gota séssil através de fotografias $10 \times 15 \mathrm{~cm}$. Os líquidosteste utilizados como parâmetro foram meio de cultura BHI estéril, água bidestilada e $p$-xileno. Este ensaio foi realizado em triplicata para cada bactéria e material testado. Foi considerado que maior ângulo de contato para um líquido polar, como água bidestilada e meio de cultura BHI, indica menor interação deste com a camada superficial, sugerindo maior hidrofobicidade da superfície testada; para um líquido mais apolar, como p-xileno, menor ângulo de contato indica maior interação e superfície menos hidrofóbica ${ }^{(22-23)}$.

\section{Avaliação da aderência através da contagem de U.F.C.}

Antes de cada teste de aderência, o microrganismo foi semeado em ágar-sangue $5 \%$ e incubado por 16 a 24 horas a $37^{\circ} \mathrm{C}$. Posteriormente, foram inoculados $200 \mu \mathrm{l}$ de cada amostra de $S$. aureus, S. epidermidis e P. aeruginosa em tubos contendo $5 \mathrm{~mL}$ de caldo BHI e incubados novamente a $37^{\circ} \mathrm{C}$ em agitador com velocidade de $100 \mathrm{~g}$.

Após 12 horas de incubação, uma alíquota foi diluída 1:10 com tampão fosfato (PBS) e determinada a $\mathrm{DO}_{60}$ para calcular o volume do inóculo correspondente à DO de 0,01. O inóculo foi colocado em Erlenmayer contendo $100 \mathrm{~mL}$ de BHI e incubado por 6 horas a $37^{\circ} \mathrm{C}$ em agitador juntamente com as LIO de PMMA e de silicone. As suspensões foram, então, vertidas em tubos Falcon de $50 \mathrm{~mL}$ e os microrganismos colhidos após centrifugação por 30 minutos a $4000 \mathrm{~g}$ (INTERNATIONAL, Alemanha). O sedimento foi lavado por 2 vezes em $2 \mathrm{~mL}$ de PBS e ressuspendido em $20 \mathrm{~mL}$ de PBS. Esta suspensão foi plaqueada em meio sólido TSB pela técnica de "drop plate" e incubada por 12 horas a $30^{\circ} \mathrm{C}$ para contagem das Unidades Formadoras de Colônia (U.F.C.mL ${ }^{-1}$ ).

Após a última incubação, as lentes intra-oculares foram retiradas das suspensões e lavadas com $10 \mathrm{~mL}$ de PBS por duas vezes. De forma individualizada, as lentes foram colocadas em $5 \mathrm{~mL}$ de PBS para sonicação por 2 períodos de 10 minutos a $40 \mathrm{kHz} \pm 6 \mathrm{kHz}$ (UNIQUE Ultrasonic Cleaner modelo USC 700, São Paulo-SP). Quatro diluições de cada sonicado foram preparadas em PBS $\left(10^{-1}, 10^{-2}, 10^{-3}\right.$ e $\left.10^{-4}\right)$ e alíquotas de $10 \mathrm{ml}$ de cada diluição foram inoculadas em placas com meio TSB, divididas em 10 setores. Após incubação por 12 horas a $30^{\circ} \mathrm{C}$, foram contadas as U.F.C.mL ${ }^{-1}$ para verificar-se a aderência dos microrganismos em cada amostra. 


\section{Avaliação da aderência bacteriana e formação de biofilme por microscopia}

A aderência bacteriana às lentes intra-oculares de PMMA e de silicone foi também avaliada por microscopia óptica (coloração de Gram) e microscopia eletrônica de varredura (MEV). A produção de biofilme foi avaliada por microscopia de força atômica (MFA).

\section{Microscopia óptica}

Após a incubação inicial, os materiais foram retirados e lavados com PBS. Para cada material foram realizadas duas colorações de Gram: uma sem sonicação do material e outra após sonicação em dois intervalos de 10 minutos a uma freqüência de $40 \mathrm{kHz} \pm 6 \mathrm{kHz}$.

\section{Microscopia eletrônica de varredura (MEV)}

A preparação do material para a MEV foi realizada segundo o método descrito por Englert ${ }^{(24)}$. Resumidamente, as lentes foram primeiramente lavadas em PBS $\mathrm{pH} 7,4$ por duas vezes. A seguir, foram fixadas em glutaraldeído $1 \%$ por um período de 12 horas e, então, lavadas em PBS por duas vezes. A seguir, as amostras foram desidratadas com etanol em concentrações crescentes de $50 \%, 70 \%, 80 \%, 95 \%$ e $100 \%$, com intervalo de 20 minutos entre cada troca. Após secarem à temperatura ambiente, as amostras foram imediatamente metalizadas com ouro utilizando-se o Sputtering (Balzers Union SCD040). Foram examinadas várias áreas na superfície das lentes intraoculares em microscópio PHILIPS.

\section{Microscopia de força atômica (MFA)}

A MFA foi utilizada para verificar a presença de biofilme. Os três microrganismos foram inoculados individualmente em $5 \mathrm{~mL}$ de BHI e, após a introdução das LIO, os tubos foram incubados a $37^{\circ} \mathrm{C}$ por 12 horas com leve agitação. A seguir, os materiais foram retirados da suspensão, enxaguados levemente com PBS estéril por duas vezes e imersos em glutaraldeído $1 \%$ (contendo sacarose) por 12 horas para a fixação dos microrganismos. Após serem removidas do glutaraldeído, as lentes foram lavadas novamente com PBS por duas vezes e secadas em estufa. A visualização foi realizada em microscópio de força atômica NANOSCOPE IIIA (Digital Instruments, Santa Bárbara, CA, USA).

\section{Análise estatística}

Para a avaliação estatística dos dados obtidos nos testes de aderência foi utilizada a análise de variância (ANOVA). Nos grupos em que foram constatadas diferenças estatisticamente significativas foi utilizado o teste de Tukey. No teste do xileno e no ensaio de hidrofobicidade foi utilizado o teste t-Student. Todas as análises foram realizadas observando-se um nível de significância $(\alpha)$ de 0,05 .

\section{RESULTADOS}

Para a verificação de presença de cápsula os resultados foram comparados aos obtidos com Klebsiella pneumoniae, usada como controle positivo. As três cepas analisadas pelos três métodos diferentes produziram cápsula quando comparadas à cepa controle de Klebsiella pneumoniae sendo, no entanto, observadas algumas diferenças de um método para outro (Tabela 1).

A microscopia óptica demonstrou presença de cápsula em todos os microrganismos, enquanto o método qualitativo mostrou que Staphylococcus aureus, Staphylococcus epidermidis e Pseudomonas aeruginosa apresentaram moderada intensidade de cor, quando comparados à Klebsiella pneumoniae utilizada como controle positivo.

No micrométodo quantitativo $K$. pneumoniae apresentou uma média de absorbância de 1,97 $\pm 0,08, P$. aeruginosa de $1,93 \pm 0,07$, S. aureus de $1,90 \pm 0,07$ e S. epidermidis de 1,95 \pm 0,06 , não havendo diferença estatisticamente significativa entre esses valores. As médias foram obtidas a partir de 15 repetições para cada bactéria.

As medidas dos ângulos do raio pela técnica de gota séssil com líquidos-teste nos diferentes materiais demonstraram ângulos maiores em LIO de silicone, possivelmente por serem materiais mais hidrofóbicos; ângulos menores foram observados em LIO de PMMA, com exceção do xileno (Tabela 2). O valor 0,00 para LIO de PMMA com xileno foi colocado pela impossibilidade de se medir o ângulo do raio da gota séssil.

A tabela 3 mostra os resultados obtidos pelas três técnicas testadas para a avaliação da hidrofobicidade dos microrganismos testados. O teste de agregação salina, realizado com concentrações crescentes de sulfato de amônio, demonstrou que com S. aureus houve formação de grumos em concentração igual ou superior a $1,5 \mathrm{M} \mathrm{e} P$. aeruginosa na concentração

\begin{tabular}{|c|c|c|c|}
\hline \multicolumn{4}{|c|}{ Tabela 1. Avaliação da presença de cápsula } \\
\hline Microrganismo & $\begin{array}{l}\text { roscopia } \\
\text { óptica }\end{array}$ & $\begin{array}{l}\text { Método } \\
\text { qualitativo }\end{array}$ & $\begin{array}{r}\text { Micrométodo } \\
\text { quantitativo }\end{array}$ \\
\hline $\begin{array}{l}\text { Klebsiella pneumoniae } \\
\text { (controle positivo) }\end{array}$ & + & +++ & $1,97 \pm 0,08$ \\
\hline Staphylococcus aureus & + & ++ & $1,90 \pm 0,07$ \\
\hline Staphylococcus epidermidis & + & ++ & $1,95 \pm 0,06$ \\
\hline Pseudomonas aeruginosa & + & ++ & $1,92 \pm 0,07$ \\
\hline \multicolumn{4}{|c|}{$\begin{array}{l}\text { Na microscopia óptica a presença de cápsula é indicada por cruzes (+); no } \\
\text { método qualitativo os valores de intensidade de cor da safranina são expressos } \\
\text { em cruzes (+); no micrométodo quantitativo os valores representam a média } \\
\text { e desvio padrão das medidas da absorbância a } 490 \mathrm{~nm} \text { em } 15 \text { repetições }\end{array}$} \\
\hline
\end{tabular}

\begin{tabular}{|llcc|}
\hline \multicolumn{4}{|c|}{ Tabela 2. Avaliação da hidrofobicidade } \\
Água & $\begin{array}{c}\text { Meio de } \\
\text { bidestilada }\end{array}$ & Xultura BHI & Xileno \\
LIO de PMMA & $41,00 \pm 2,83$ & $36,00 \pm 1,41$ & 0,00 \\
LIO de silicone & $57,00 \pm 4,24$ & $53,00 \pm 0,00$ & $35,00 \pm 2,83$ \\
Técnica da gota séssil através da medida do ângulo do raio (em graus) em \\
superfícies de lentes intra-oculares (LIO) de polimetilmetacrilato (PMMA) e de \\
silicone, utilizando-se água bidestilada, meio de cultura BHI e p-xileno como \\
líquidos-teste. \\
BHI - caldo de infusão de cérebro e coração \\
\hline
\end{tabular}




\begin{tabular}{|c|c|c|c|c|c|}
\hline \multirow[t]{2}{*}{ Microrganismo } & \multirow[t]{2}{*}{ Teste de agregação salina } & \multicolumn{2}{|c|}{ Teste do Xileno } & \multicolumn{2}{|c|}{ Ângulo do raio da gota séssil (graus) } \\
\hline & & $\mathrm{DO}_{\mathrm{i}}$ & $\mathrm{DO}_{\mathrm{f}}$ & LIO Silicone & LIO PMMA \\
\hline S. aureus & $\geq 1,5 \mathrm{M}$ & $0,821 \pm 0,005$ & $0,664 \pm 0,014$ & $44,00 \pm 0,00$ & $55,67 \pm 4,04$ \\
\hline S. epidermidis & $>3,0 \mathrm{M}$ & $0,836 \pm 0,038$ & $0,475 \pm 0,034$ & $42,67 \pm 2,31$ & $58,50 \pm 0,71$ \\
\hline$P$. aeruginosa & $\geq 2,5 \mathrm{M}$ & $0,847 \pm 0,022$ & $0,824 \pm 0,019$ & $41,67 \pm 1,53$ & $57,33 \pm 1,15$ \\
\hline
\end{tabular}

igual ou superior a 2,5M, sugerindo que estas cepas têm uma tendência hidrofóbica moderada. Porém, $S$. epidermidis não formou grumos na concentração mais elevada de $3 \mathrm{M}$, levando-nos a acreditar que esta cepa tenha uma característica hidrofílica neste ensaio.

O teste realizado com xileno revelou algumas diferenças em comparação ao teste de agregação salina. Utilizando o teste estatístico t-pareado, constatamos que $S$. aureus e o $S$. epidermidis tiveram diferenças estatisticamente significativas onde o t calculado foi igual a 9,76 e 12,14, respectivamente. Para $P$. aeruginosa, que não apresentou diferença estatisticamente significativa em relação aos estafilococos, o t calculado foi igual a 1,60 .

Em relação à medida do ângulo do raio pela técnica da gota séssil as suspensões dos microrganismos contendo $10^{6}$ células $/ \mathrm{mL}$ não apresentaram diferenças estatisticamente significativas para os tipos de lentes analisadas.

A tabela 4 mostra os valores encontrados na avaliação da aderência bacteriana às LIO. Não houve diferença estatisticamente significativa entre os estafilococos, enquanto Pseudomonas aeruginosa foi a bactéria mais aderente aos diferentes materiais testados.

Pela coloração de Gram no material não sonicado, verificou-se que tanto estafilococos quanto Pseudomonas aderiram eficientemente às LIO, com $P$. aeruginosa aderindo em maior número. No material sonicado verificamos que os estafilococos se desprenderam consideravelmente, o mesmo não acontecendo com $P$. aeruginosa (resultados não mostrados).

A figura 1 mostra imagens de bactérias aderidas às lentes intra-oculares, obtidas por microscopia eletrônica de varredura. Pela microscopia de força atômica foi possível verificar-se a

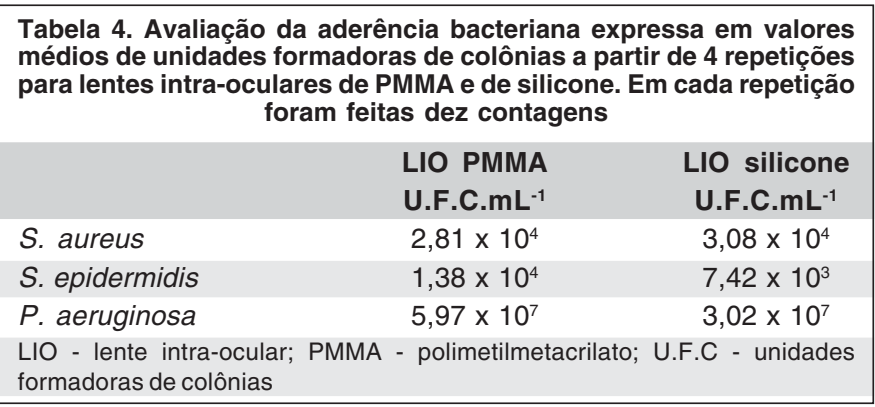

presença de biofilme produzido pelas cepas de $S$. aureus, $S$. epidermidis e $P$. aeruginosa em ambos tipos de lentes. Na figura 2 são mostradas imagens de biofilme formado por $S$. aureus e $P$. aeruginosa.

\section{DISCUSSÃO}

As cepas de $S$. aureus, S. epidermidis e $P$. aeruginosa, analisadas pelos métodos de microscopia óptica, método qualitativo e micrométodo quantitativo, produziram cápsula quando comparadas à cepa controle de Klebsiella pneumoniae sendo, no entanto, observadas algumas diferenças de um método para outro (Tabela 1).

O micrométodo quantitativo demonstrou que em relação à $K$. pneumoniae, a cepa de $S$. aureus provavelmente produziu menor quantidade de cápsula, visto que houve diferença estatisticamente significativa entre estas cepas. De acordo com este método, $S$. epidermidis e $P$. aeruginosa seriam fortes produtores de cápsula. Utilizando a mesma técnica ${ }^{(21)}$, foi verificada a aderência de cepas bacterêmicas de S. epidermidis ao poliestireno, com as 20 cepas avaliadas, sendo incluídas em três grupos: fortemente (5), moderadamente (4) e fracamente produtoras ou não-produtoras de cápsula (11), conforme a densidade óptica.

Diversos trabalhos têm estudado a produção de cápsula em estafilococos e tentado estabelecer sua relação com aderência bacteriana a materiais. Um deles verificou, em pacientes com sepsis, que $63 \%$ das cepas de S. epidermidis isoladas de cateteres intravasculares produziam cápsula, o que ocorria em somente $37 \%$ das cepas isoladas da pele. Os autores concluíram, ainda, que a produção ou não de cápsula não influenciava no crescimento, mas que $S$. epidermidis produtores de cápsula estariam relacionados à adesão a superfícies de biomateriais ${ }^{(20)}$. Em outro estudo, quando foi testada a adesão de estafilococos coagulase-negativos a biomateriais através dos métodos "film-wet" e "Muir", verificou-se que S. epidermidis, embora não sendo produtor de cápsula ou biofilme, mostrou maior adesão do que $S$. saprophyticus que era cápsula-positi$\mathrm{vo}^{(25)}$. Recentemente, foram utilizados os métodos qualitativo e quantitativo da safranina para avaliar a aderência de cepas de $S$. epidermidis produtoras e não produtoras de cápsula a diferentes tipos de LIO. As cepas cápsula-positivas foram mais aderentes do que as cápsula-negativas ${ }^{(26)}$. 

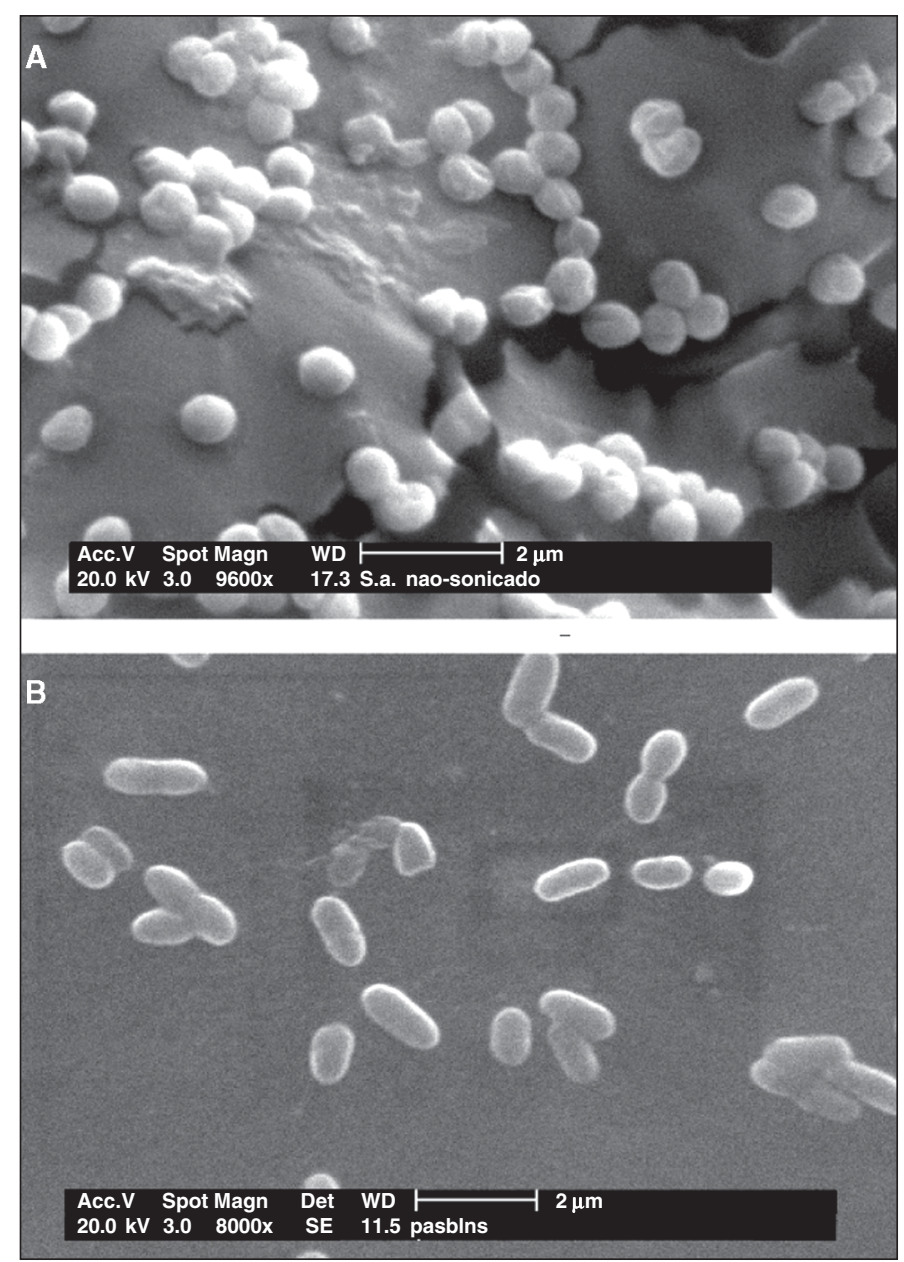

Figura 1 - Imagens de bactérias aderidas às lentes intra-oculares por microscopia eletrônica de varredura: A - Staphylococcus aureus aderidos à lente de polimetilmetacrilato; B - Pseudomonas aeruginosa aderidos à lente de silicone

Nas condições experimentais testadas em nosso trabalho, não ficou demonstrada a associação entre formação de cápsula e adesão aos materiais, conforme pode ser verificado nas tabelas 1 e 4. Na tabela 1, S. epidermidis demonstrou, pelo micrométodo quantitativo, ser maior produtor de cápsula em relação aos outros microorganismos, porém, não foi mais aderente às LIOs de PMMA e silicone do que $P$. aeruginosa (Tabela 4). Isto fortalece a hipótese de que a relação entre a superfície do material e a do microorganismo é de extrema importância quanto ao aspecto da aderência.

Através de um modelo in vitro, foi demonstrado que a aderência de Staphylococcus epidermidis a lentes intra-oculares estava associada à produção de glicocálix polissacarídico e que tanto cepas produtoras quanto não-produtoras de cápsula aderiam firmemente, não havendo diferença estatisticamente significativa no número de microrganismos aderi$\operatorname{dos}^{(15)}$. Outro autor, demonstrou que 15 a $20 \%$ de cepas de $S$. epidermidis isoladas da conjuntiva humana podem produzir cápsula e biofilme e, uma vez aderidas à lente intra-ocular,
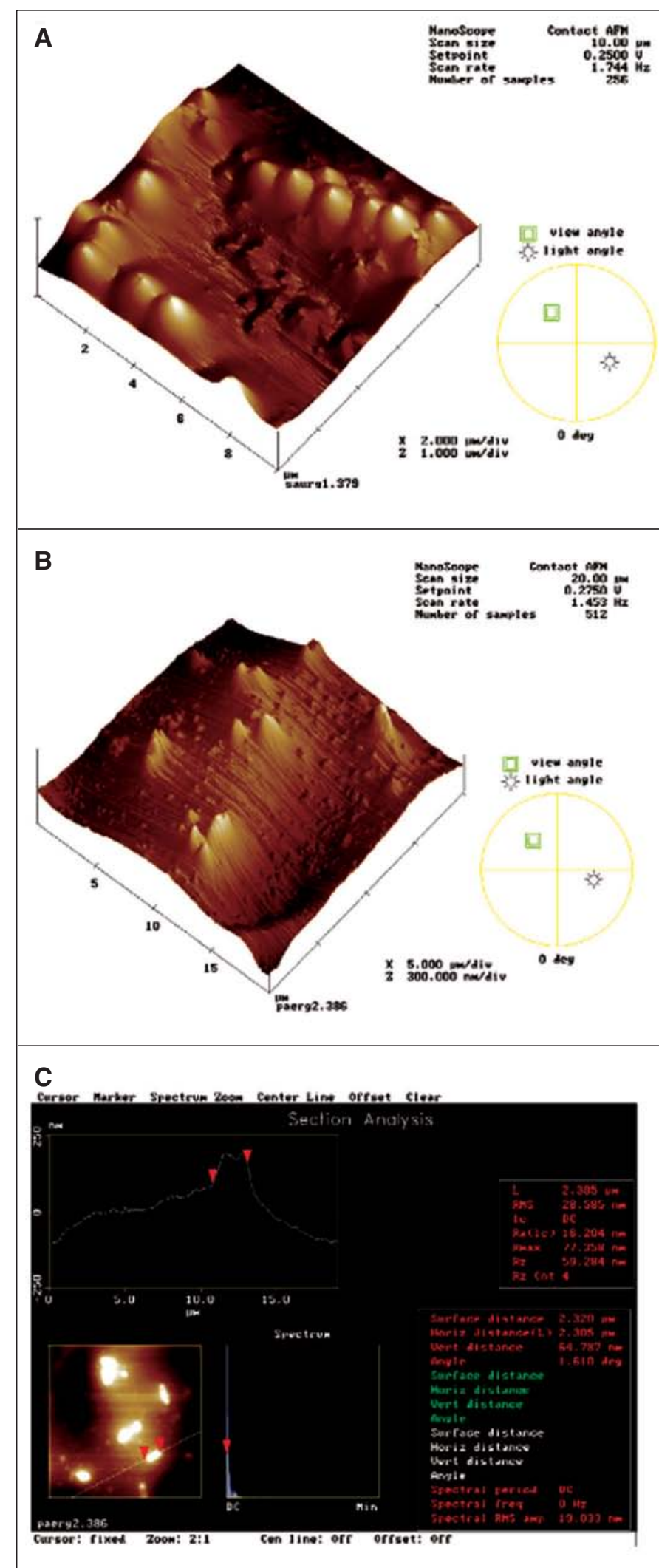

Figura 2 - Imagens de bactérias aderidas às lentes intra-oculares por microscopia de força atômica, evidenciando a presença de biofilme: A - Staphylococcus aureus aderidos à lente de polimetilmetacrilato; B - Pseudomonas aeruginosa aderidos à lente de silicone; C - Análise seccional de Pseudomonas aeruginosa aderidos à lente de silicone 
provocarem infecção ${ }^{(27)}$. No entanto, outros pesquisadores acreditam que a produção de cápsula e a expressão do antígeno associado à cápsula por isolados clínicos de estafilococos têm forte associação com a habilidade de produzir espessos biofilmes e possivelmente com a virulência do S. epidermi$d i s^{(12)}$. Em outro estudo, ficou demonstrado que a média de produção de biofilmes de 22 isolados de S. epidermidis a partir de cateteres relacionados com bacteremia foi significativamente mais alta do que os 32 isolados do nariz de indivíduos saudáveis ${ }^{(28)}$. Paralelamente, neste caso, não foi encontrada uma clara associação entre produção de biofilme e virulência.

Em nosso estudo houve produção de biofilme (Figura 2) por todas as cepas testadas, porém, não foi possível estabelecer associação entre produção de cápsula e biofilme.

Estudos têm demonstrado que a hidrofobicidade da superfície bacteriana pode desempenhar um papel muito importante nos fenômenos de adesão celular ${ }^{(21,23,25,29-33)}$, embora haja muita discrepância nos resultados relatados na literatura. De acordo com outro trabalho, na fase exponencial de crescimento as bactérias tendem a se tornar mais hidrofóbicas e formar grumos, aderindo umas às outras ou a superfícies presentes no meio de cultura ${ }^{(34)}$. Em nosso estudo isto foi constatado com culturas de $S$. aureus e $P$. aeruginosa, porém, S. epidermidis não apresentou este comportamento quando se utilizou o teste de agregação com sulfato de amônio.

Em função dos resultados do teste realizado com xileno no presente trabalho, pode-se inferir que as cepas de $S$. aureus e $S$. epidermidis possuem uma característica hidrofóbica diferentemente de $P$. aeruginosa que se mostrou hidrofílica (Tabela 3). Não foram utilizados microrganismos como controles positivos e negativos pelo fato de se desconhecer as propriedades superficiais dos mesmos e, ainda, por este ser um fator relativo.

Embora as discrepâncias observadas entre os resultados encontrados nas três técnicas utilizadas para verificar a hidrofobicidade dos materiais, os resultados mostraram que as tensões superficiais sobre a superfície de LIO de PMMA com suspensões de $S$. aureus, $S$. epidermidis e $P$. aeruginosa tiveram um comportamento com tendência à hidrofilicidade, quando comparadas ao comportamento dos mesmos microrganismos em relação à superfície de LIO de silicone, as quais tiveram uma propriedade ligeiramente hidrofóbica (Tabela 3 ).

A idéia de que materiais com superfície hidrofílica possuiriam menor capacidade de atrair as bactérias ${ }^{(14)}$ pode não ser verdadeira como ficou demonstrado em nosso trabalho, ao analisarmos as tabelas 3 e 4 . Recentemente foi demonstrado que a aderência bacteriana envolve interações complexas entre a cepa bacteriana e a superfície do biomaterial. Bactérias com superfície hidrofóbica teriam menor tendência a colonizarem as superfícies hidrofílicas. No entanto, quando se utilizaram bactérias com superfícies hidrofílicas, os resultados inverteram-se $\mathrm{e}^{(11)}$. Outra pesquisa anterior já havia demonstrado que o papel das bactérias era tão ou mais importante que o da superfície polimérica ${ }^{(35)}$.
Analisando a adesão inicial e o crescimento superficial de $P$. aeruginosa e $S$. epidermidis em polímeros biomédicos, os autores concluíram que a superfície de crescimento de bactérias que aderem inicialmente é influenciada pelas propriedades da grande maioria dos biomateriais, observando que $P$. aeruginosa aderiu mais firmemente ao substrato e que somente a força de aderência do S. epidermidis dependeu da hidrofobicidade do substrato ${ }^{(36-37)}$. Mesmo tendo demonstrado uma tendência de hidrofobicidade da superfície celular microbiana, outros autores verificaram que não houve correlação entre diferentes isolados de microrganismos e carga superficial ce$\operatorname{lular}^{(38)}$. Pesquisadores demonstraram que a aderência bacteriana diminui com a diminuição do ângulo de contato e aumento da tensão superficial dos materiais sintéticos ${ }^{(22)}$. Para a adesão não específica inicial de células bacterianas ter sucesso na colonização, outros tipos específicos de adesão são provavelmente requeridos. A adesão de $S$. epidermidis às superfícies de cateteres é facilitada por um antígeno produtor de cápsula o qual é rico em galactose, sendo que mais de um tipo de adesina pode estar envolvido com a aderência de S. epidermidis aos biomateriais ${ }^{(39)}$.

Não foram encontradas diferenças estatisticamente significativas, in vitro, entre as taxas de aderência de $S$. aureus e $S$. epidermidis sobre as lentes intra-oculares de silicone e de PMMA, porém $P$. aeruginosa foi o microrganismo mais aderente às mesmas (Tabela 4 ). Na figura 1 pode-se observar a aderência de $S$. aureus e $P$. aeruginosa a lentes intra-oculares. Outros estudos têm testado as propriedades das diferentes lentes intra-oculares atraírem bactérias. A maior parte dos estudos utilizou modelos in vitro com cepas de Staphylococcus epidermidis produtoras de biofilme. Os resultados têm sido controversos. Comparando lentes de hidrogel com lentes de PMMA, foi encontrada uma menor aderência às lentes de hidrogel ${ }^{(40)}$, enquanto em outro trabalho prévio, descrevem que as lentes de PMMA tiveram menor adesão ${ }^{(18)}$.

A aderência de Pseudomonas aeruginosa foi comparada em quatro tipos de lentes intra-oculares' sendo que a menor aderência ocorreu em lentes de acrílico, enquanto que as lentes de silicone foram as que apresentaram a mais alta aderência bacteriana ${ }^{(41)}$. Utilizando-se de cepas de Staphylococcus epidermidis, também encontraram uma maior aderência bacteriana às lentes de silicone quando estas foram comparadas com lentes de PMMA, lente de PMMA com superfície modificada por heparina (HSM-PMMA) e hidrogel ${ }^{(18,42)}$. Estes estudos contrariam nossos achados, em que não houve diferença estatisticamente significativa na aderência in vitro entre os diversos materiais e os microrganismos estudados. Esta diferença poderia ser verdadeira no passado, pois atualmente o silicone é manufaturado a partir de matéria-prima que sofre tratamento antiaderente.

A utilização de modelos que simulem a contaminação bacteriana dos polímeros é muito importante para o aperfeiçoamento dos mesmos. Não há dúvida de que as diferenças entre as diversas metodologias empregadas podem explicar parcialmente os resultados distintos destas pesquisas. Entre os fatores 
que influenciam a adesão bacteriana aos biomateriais estão a concentração de bactérias em contato com os mesmos, bem como o tempo de exposição dos polímeros aos microrganis$\operatorname{mos}^{(43)}$. Em modelos prévios, foi utilizada uma grande concentração bacteriana (em média de $10^{6}$ U.F.C.mL ${ }^{-1}$ ), quando sabemos que a quantidade de bactérias presentes no olho durante a cirurgia é bem menor, ou seja, culturas provenientes do humor aquoso revelam uma média de 10 -20 U.F.C.mL ${ }^{-1}$. O tempo que as bactérias permanecem em contato com a lente intra-ocular ainda é uma incógnita, uma vez que existe o contato imediato, mediado por forças eletrostáticas e de apenas alguns segundos durante a inserção da lente no olho; entretanto, sabe-se que no final da cirurgia, ainda permanecem bactérias viáveis na câmara anterior por um período indeterminado ${ }^{(44)}$.

A importância dos diversos fatores envolvidos na aderência dos microrganismos a superfícies ainda deve ser melhor e mais claramente estabelecida. Devemos também considerar que, muitas vezes, a capacidade de aderência verificada in vitro não reflete o que ocorre no processo natural de infecção. Portanto, serão necessários mais estudos para que se possa correlacionar de uma forma mais segura os processos de interação verificados in vitro com os mecanismos de patogenicidade destes microrganismos in vivo, a fim de que se possa reduzir o risco de contaminação de material utilizado em facectomia para implante de lente intra-ocular.

\section{CONCLUSÕES}

Em nosso estudo houve produção de biofilme e cápsula por todas as cepas testadas, porém, não foi possível estabelecer associação entre eles. Não houve correlação significativa ou associação entre produção de cápsula e aderência bacteriana às lentes intra-oculares de PMMA e de silicone.

Das bactérias testadas in vitro, Pseudomonas aeruginosa foi a mais aderente às lentes intra-oculares de PMMA e de silicone.

Não foram encontradas diferenças estatisticamente significativas, in vitro, nas taxas de aderência de Staphylococcus aureus, Staphylococcus epidermidis e Pseudomonas aeruginosa comparando-se as lentes intra-oculares de silicone e de PMMA.

Constatamos, através da medida do ângulo do raio da gota séssil, que o silicone foi o material mais hidrofóbico, quando comparado ao PMMA.

\section{AGRADECIMENTOS}

Os autores agradecem ao Laboratório CILCO ${ }^{\circledR}$ Alcon Surgical, Inc. (Fort Worth, Texas - USA) que providenciaram LIO's de PMMA; ao Laboratório Allergan Medical Optics ${ }^{\mathrm{TM}}$ (Irvine, Califórnia -USA) pelo fornecimento das LIO's de silicone; ao Laboratório de Microbiologia do Instituto de Ciências Básicas da Saúde (ICBS - UFRGS) onde foram desenvolvidos os estudos de aderência; ao Hospital de Clínicas de
Porto Alegre; ao Laboratório de Pesquisa em Corrosão; ao Departamento de Minas e Materiais da Universidade de Reno (Nevada - USA) por oportunizar as análises realizadas por microscopia de força atômica; às empresas Pomp Tecnologia e Metacril pelas amostras fornecidas de silicone e PMMA; e ao CNPq, o qual foi o órgão que financiou este trabalho.

\section{ABSTRACT}

Purpose: To evaluate bacterial adherence to silicone and polymetylmethacrylate (PMMA) intraocular lenses as a risk factor for postsurgery endophthalmitis by using an in vitro model with three potentially pathogenic microorganisms. Methods: In vitro experiments were carried out with the Staphylococcus aureus ATCC 29213, Staphylococcus epidermidis (clinical isolate) and Pseudomonas aeruginosa ATCC 27853 strains including growth curves, tests to verify capsule production, hydrophobicity and adherence to different materials as well as optical microscopy, scanning electronic microscopy (SEM) and atomic force microscopy (AFM). Results: No relation between capsule production, adherence of the strains tested and amount of microorganisms was observed; no statistically significant differences were detected between $S$. aureus and $S$. epidermidis adherence to polymetylmethacrylate and silicone intraocular lenses; $P$. aeruginosa was the most adherent microorganism to both materials. This adherence pattern was confirmed by SEM, while biofilm production by the three strains was visualized by AFM. Conclusions: In vitro experiments showed no differences of bacterial adherence between PMMA and silicone lenses, but $P$. aeruginosa displayed a greater level of adherence in relation to staphylococci. All three strains were shown to produce biofilm. Silicone was shown to be more hydrophobic when compared to polymethylmethacrylate.

Keywords: Bacterial adhesion; Lenses, intraocular; Polymethylmethacrylate; Silicones; Pseudomonas; Staphylococcal infections

\section{REFERÊNCIAS}

1. Miller KM, Glasgow BJ. Bacterial endophthalmitis following sutureless cataract surgery. Arch Ophthalmol 1993;111:377-9.

2. Powe NR, Schein OD, Gieser SC, Tielsch JM, Luthra R, Javitt J, Steinberg EP. Synthesis of the literature on visual acuity and complications following cataract extraction with intraocular lens implantation.Cataract Patient Outcome Research Team. Arch Ophthalmol 1994;112:239-52.

3. Kanski JJ. Clinical ophthalmology: a systematic approach. Edinburgh: Butterworth-Heinemann; 1994. [international edition].

4. Walker CB, Claoué CM. Incidence of conjunctival colonization by bacteria capable of causing postoperative endophthalmitis. J R Soc Med 1986;79:520-1.

5. Boes DA, Lindquist TD, Fritsche TR, Kalina RE. Effects of povidone-iodine chemical preparation and saline irrigation on the perilimbal flora. Ophthalmology 1992;99:1569-74.

6. Campos MS, Campos e Silva L de O, Rehder JR, Lee MB, O'Brien T, MacDonnel PJ. Anaerobic flora of the conjuntival sac in patients with AIDS and with anophthalmia compared with normal eyes. Acta Ophthalmol (Copenh) 1994;72:241-5. 
7. Chitkara DK, Manners T, Chapman F, Stoddart MG, Hill D, Jenkins D. Lack of effect of preoperative norfloxacin on bacterial contamination of anterior chamber aspirates after cataract surgery. Br J Ophthalmol 1994;78:772-4.

8. Apt L, Isenberg SJ, Yoshimori R, Chang A, Lam GC, Wachler B, Neumann D. The effect of povidone-iodine solution applied at the conclusion of ophthalmic surgery. Am J Ophthalmol 1995;119:701-5.

9. Marcon AS, Barbosa MP, Vasques CL, Marcon IM, Dorneles IC, Kader ITA Cauduro PF. Microbiota aeróbia e anaeróbia normal da conjuntiva e borda palpebral de indivíduos hígidos. Arq Bras Oftalmol 1996;59:289-94.

10. Elder MJ, Stapleton F, Evans E, Dart JK. Biofilm-related infections in ophthalmology. Eye 1995;9:102-9.

11. Schmidt H, Schlöricke E, Fislage R, Schulze HA, Guthoff R. Effect of surface modifications of intraocular lenses on the adherence of Staphylococcus epider midis. Zentralbl Bakteriol 1998;287:135-45.

12. Ammendolia MG, Di Rosa R, Montanaro L, Arciola CR, Baldassarri L. Slime production and expression of the slime-associated antigen by staphylococcal clinical isolates. J Clin Microbiol 1999;37:3235-8.

13. Locatelli CI, Kwitko, S, Simonetti, AB. Conjunctival endogenous microbiota in patients submitted to cataract surgery. Braz J Microbiol [no prelo].

14. Jansen B, Peters G, Pulverer G. Mechanisms and clinical relevance of bacterial adhesion to polymers. J Biomater Appl 1988;2:520-43.

15. Griffiths PG, Elliot TS, McTaggart L. Adherence of Staphylococcus epidermidis to intraocular lenses. Br J Ophthalmol 1989;73:402-6.

16. Townsend-Pico WA, Meyers SM, Langston RH, Costin JA. Coagulase-negative Staphylococcus endophthalmitis after cataract surgery with intraocular vancomycin. Am J Ophthalmol 1996;121:318-9.

17. Vafidis GC, Marsh RJ, Stacey AR. Bacterial contamination of intraocular lens surgery. Br J Ophthalmol 1984;68:520-3.

18. Cusumano A, Busin M, Spitznas M. Bacterial growth is significantly enhanced on foldable intraocular lenses. Arch Ophthalmol 1994;112:1015-6.

19. Seeley Jr HW, VanDemark PJ, Lee JJ. Microbes in action: a laboratory manual of microbiology. $4^{\text {th }}$ ed. New York: H. W. Freeman and Company; 1991. cap.4, p.450.

20. Christensen GD, Simpson WA, Bisno AL, Beachey EH. Adherence of slimeproducing strains of Staphylococcus epidermidis to smooth surfaces. Infect Immun 1982;37:318-26.

21. Galliani S, Viot M, Cremieux A, Van der Auwera P. Early adhesion of bacteremic strains of Staphylococcus epidermidis to polystyrene: influence of hidrophobicity, slime production, plasma, albumin, fibrinogen, and fibronectin. J Lab Clin Med 1994;123:685-92.

22. Morra M, Cassinelli C. Staphylococcus epidermidis adhesion to films deposited from hydroxyethylmethacrylate plasma. J Biomed Mater Res 1996;31: 149-55.

23. Ludwicka A, Jansen B, Waldström T, Pulverer G. Attachment of staphylococci to various synthetic polymers. Zentralbl Bakteriol Mikrobiol Hyg [A] 1984;256:479-89.

24. Englert G. Aplicação de técnicas eletroquímicas no estudo da corrosão de açocarbono e de aço inoxidável AISI 304 em presença de microrganismos [tese]. Porto Alegre: Universidade Federal do Rio Grande do Sul; 1997.

25. Hogt AH, Dankert J, de Vries JA, Feijen J. Adhesion of coagulase-negative staphylococci to biomaterials. J Gen Microbiol 1983;129:2959-68.

26. García-Sáenz MC, Arias-Puente A, Fresnadillo-Martinez MJ, Matilla-Rodri- guez A. In vitro adhesion of Staphylococcus epidemidis to intraocular lenses. J Cataract Refract Surg 2000;26:1673-9.

27. Miyanaga Y. A new perspective in ocular infection and the role of antibiotics. Ophthalmologica 1997;211 Suppl.1:9-14.

28. Vogel L, Sloos JH, Spaargaren J, Suiker I, Dijkshoorn L. Biofilm production by Staphylococcus epidermidis isolates associated with catheter related bacteremia. Diagn Microbiol Infect Dis 2000;36:139-41.

29. Dexter SC, Sullivan Jr. JD, Williams J, Watson SW. Influence of substrate wettability on the attachment of marine bacteria to various surfaces. Appl Environ Microbiol 1975;30:298-308

30. Fletcher M, Loeb GI. Influence of substratum characteristics on the attachment of a marine Pseudomona to solid surfaces. Appl Environ Microbiol 1979; 37:67-72.

31. Absolom DR, Lamberti FV, Policova Z, Zingg W, van Oss CJ, Neumann AW. Surface thermodynamics of bacterial adhesion. Appl Environ Microbiol 1983; 46:90-7.

32. Doyle RJ, Sonnenfeld EM. Properties of the cell surfaces of pathogenic bacteria. Int Rev Cytol 1989;118:33-92.

33. Neu TR. Significance of bacterial surface-active compounds in interaction of bacteria with interfaces. Microbiol Rev 1996;60:151-66.

34. van Loosdrecht MC, Lyklema J, Norde W, Schraa G, Zehnder AJ. Electrophoretic mobility and hidrophobicity as a measure to predict the initial steps of bacterial adhesion. Appl Environ Microbiol 1987;53:1898-901.

35. Petas A, Vuopio-Varkila J, Siitonen A, Välimaa T, Talja M, Taari K. Bacterial adherence to self-reinforced polyglycolic acid and self-reinforced polylactic acid 96 urological spiral stents in vitro. Biomaterials 1998;19:677-81.

36. Eginton PA, Gibson H, Holah J, Handley PS, Gilbert P. The influence of substratum properties on the attachment of bacterial cells. Colloid Surf 1995;5B:153-9.

37. Gottenbos B, van der Mei HC, Busscher HJ. Initial adhesion and surface growth of Staphylococcus epidermidis and Pseudomonas aeruginosa on biomedical polymers. J Biomed Mater Res 2000;50:208-14.

38. Jones DS, Adair CG, Mawhinney WM, Gorman SP. Standardisation and comparison of methods employed for microbial cell surface hydrophobicity and charge determination. Int J Pharm 1996;131:83-9.

39. Kloos WE. Staphylococcus. In: Collier L, editor. Balows A, Sussman M. Topley and Winson's microbiology and microbial infections. $9^{\text {th }}$ ed.[CDROM Windows 3.1]. London: Arnold; 1998. v. 2.

40. Ng EM, Barrett GD, Bowman R. In vitro bacterial adherence to hydrogel and poly (methyl methacrylate) intraocular lenses. J Cataract Refract Surg 1996;22 Suppl. 2:1331-5.

41. Gabriel MM, Ahearn DG, Chan KY, Patel AS. In vitro adherence of Pseudomonas aeruginosa to four intraocular lenses. J Cataract Refract Surg 1998;24: 124-9.

42. Prosdocimo G, Grandesso S, Amici G. Influence of optic and haptic materials on the adherence of Staphylococcus epidermidis to intraocular lens: a pilot study. Eur J Ophthalmol 1997;7:241-4.

43. Merritt K, Chang CC. Factors influencing bacterial adherence to biomaterials. J Biomater Appl 1991;5:185-203.

44. Agrawal V, Gopinathan U, Singh S, Reddy M, Rao GN. Influence of intraocular lenses haptic material on bacterial isolates from anterior chamber aspirate. J Cataract Refract Surg 1997;23:588-92.

\section{Ao enviar um artigo para publicação,} leia ATENTAMENTE as instruções para autores, constante no final de cada fascículo. 